\title{
PAISAGEM EM CONFLITO: NATUREZA, RESERVA AMBIENTAL E TERRITÓRIO INDÍGENA EM IRAÍ, RIO GRANDE DO SUL (SÉCULO XX)
}

\author{
JAISSON TEIXEIRA LINO ${ }^{1}$ \\ UFFS, BRASIL
}

FÁBIO ARAÚJO'

UFFS, BRASIL

\begin{abstract}
RESUMO: $O$ presente artigo analisa alguns documentos escritos que mostram aspectos da paisagem do município de Iraí-RS, no decorrer do século $X X$, havendo como pano de fundo os conflitos pela posse de um território localizado no interior desse municipio, entre Kaingang e não indígenas. A partir de um enfoque teórico e metodológico que abarca a história ambiental e a paisagem histórica, buscamos situar essas disputas conectadas com os discursos de individuos e grupos sociais interessados na criação/manutenção de uma suposta natureza pristina. A natureza da área em tela se torna, nesses discursos, uma ferramenta política, em ações-judiciais ou não - que tenta(ra)m impedir a presença indígena na área. O debate mantém-se atual na medida em que o território sul-brasileiro continua servindo como cenário para intensos conflitos sociais e étnicos, sobretudo no que concerne às disputas por terra.
\end{abstract}

PALAVRAS-CHAVE: Paisagem; povos indígenas; natureza; história.

ABSTRACT: This article analyzes some written documents that show aspects of the Irai-RS city landscape, in the course of the twentieth century, having as background the conflicts over the possession of a territory located inside this municipality, Kaingang and non-indigenous people. Based on a theoretical and methodological approach that encompasses environmental history and the historical landscape, we seek to situate these disputes connected with the discourses of individuals and social groups interested in the creation / maintenance of a supposed pristine nature. The nature of the area on canvas becomes, in these discourses, a political tool, especially in actions - judicial or otherwise - that tries to prevent the indigenous presence in the area. The debate remains current as South American territory continues to serve as a backdrop for intense social and ethnic conflicts, especially as regards land disputes.

KEYWORDS: Landscape; indigenous people; nature; history.

\footnotetext{
${ }^{1}$ Pós-Doutor pela Universidade de Amsterdã, Holanda. Doutor em Arqueologia pela Universidade de Trásos-Montes e Alto-Douro (UTAD) de Portugal. Docente do Programa de Pós-Graduação em História na Universidade Federal da Fronteira Sul - UFFS, Campus Chapecó-SC. E-mail: lino@uffs.edu.br

${ }^{2}$ Mestre em História pela Universidade Federal da Fronteira Sul - UFFS, Campus Chapecó-SC. E-mail: fabio.ecohi@gmail.com
} 
Espaço Ameríndio

\section{Introdução}

Iraí é um município localizado na região do Médio Alto Uruguai do Estado do Rio Grande Sul, (vide Figura 1), contando atualmente com oito mil habitantes, de acordo com dados da Federação de Economia e Estatística (FEE) do Rio Grande do Sul. Constituído como municipalidade em 1933, foi ocupado primeiramente por povos indígenas Kaingang e Guarani desde pelo menos dois mil anos antes do presente (LINO, 2015) e por populações de origem europeia desde pelo menos meados do século XIX (RADIN, 2015).

Seu ambiental natural é composto por relevos, em sua maioria do tipo acidentados, com solos basálticos pobres em nutrientes em boa parte do seu território. A vegetação possui grande variabilidade, com áreas ocupadas por matas de araucária, ciliares e campinas. O clima é do tipo subtropical, com duas estações bem definidas: inverno frio e verão quente e seco, com temperaturas anuais médias de $20^{\circ} \mathrm{C}$ (IBGE, 1977). Contudo, a água é seu componente ambiental mais importante e destacado: Iraí é banhada pelos rios Uruguai, da Várzea e do Mel (vide figura 1) e em seu território encontra-se uma famosa estância hidromineral (FISCHER, 1954; GRASSI, 1992; LAC, 2005).

Figura 1: Localização geográfica da área de estudo, com destaque para a Terra Indígena Iraí.

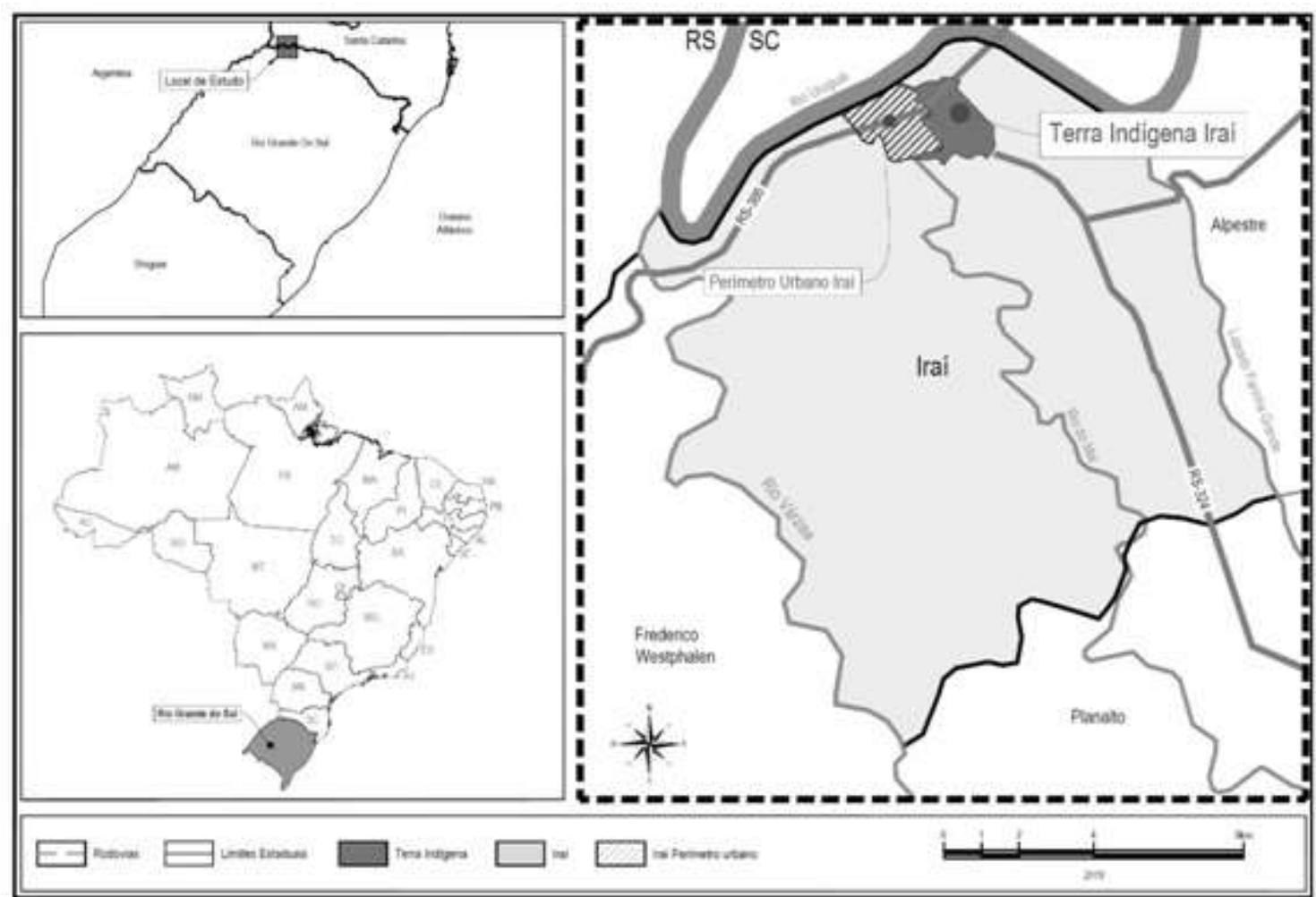

Fonte: Desenho de Mauro Fusinatto e Jaisson Teixeira Lino

Com a inter-relação entre os dois aspectos de Iraí acima descritos sua história e seu ambiente - buscamos contribuir para a reflexão 
histórica sobre alguns elementos da paisagem iraiense, sobretudo nos embates que contrapõem indígenas e não indígenas na área em tela. A partir da análise de alguns documentos, procuramos observar como determinados agentes - indivíduos ou entidades públicas e privadas objetivam a paisagem, levando-se em conta um cenário histórico muito particular: os conflitos por terra entre indígenas e não indígenas.

Desde a primeira metade do século $X X$, o povo Kaingang de Iraí vem lutando politicamente por suas demandas, culminando, dentre sua agenda de reivindicações, com a criação de uma terra indígena demarcada pela Funai em 1993, denominada Terra Indígena Iraí. Ao longo do século passado, e além, os indígenas Kaingang daquela área têm sido objeto de ações judiciais e argumentos individuais e coletivos contra a presença deles, arguindo-se em muitos casos que tal população não é originária de Iraí, ou, o que é quase dizer a mesma coisa, que, por serem nômades, não detinham a posse da referida terra (ARAÚJO, 2018).

A seguir, exploramos um ato de envergadura histórica relevante nos embates estabelecidos entre indígenas e não indígenas em Iraí: a criação de uma reserva ambiental em 1979 (IRAí, 1979) e que, dentre as premissas básicas de seus idealizadores, não caberia a possibilidade de habitação da área em tela, por parte dos indígenas, que supostamente agiriam na "destruição" do meio ambiente. Antes, porém, realizaremos um breve debate referente à paisagem como objeto histórico e uma amostra de como os documentos narram uma paisagem pristina de Iraí, que está intimamente associada ao turismo de recursos naturais.

Figura 2: Rio Uruguai, a partir da margem de Iraí-RS.

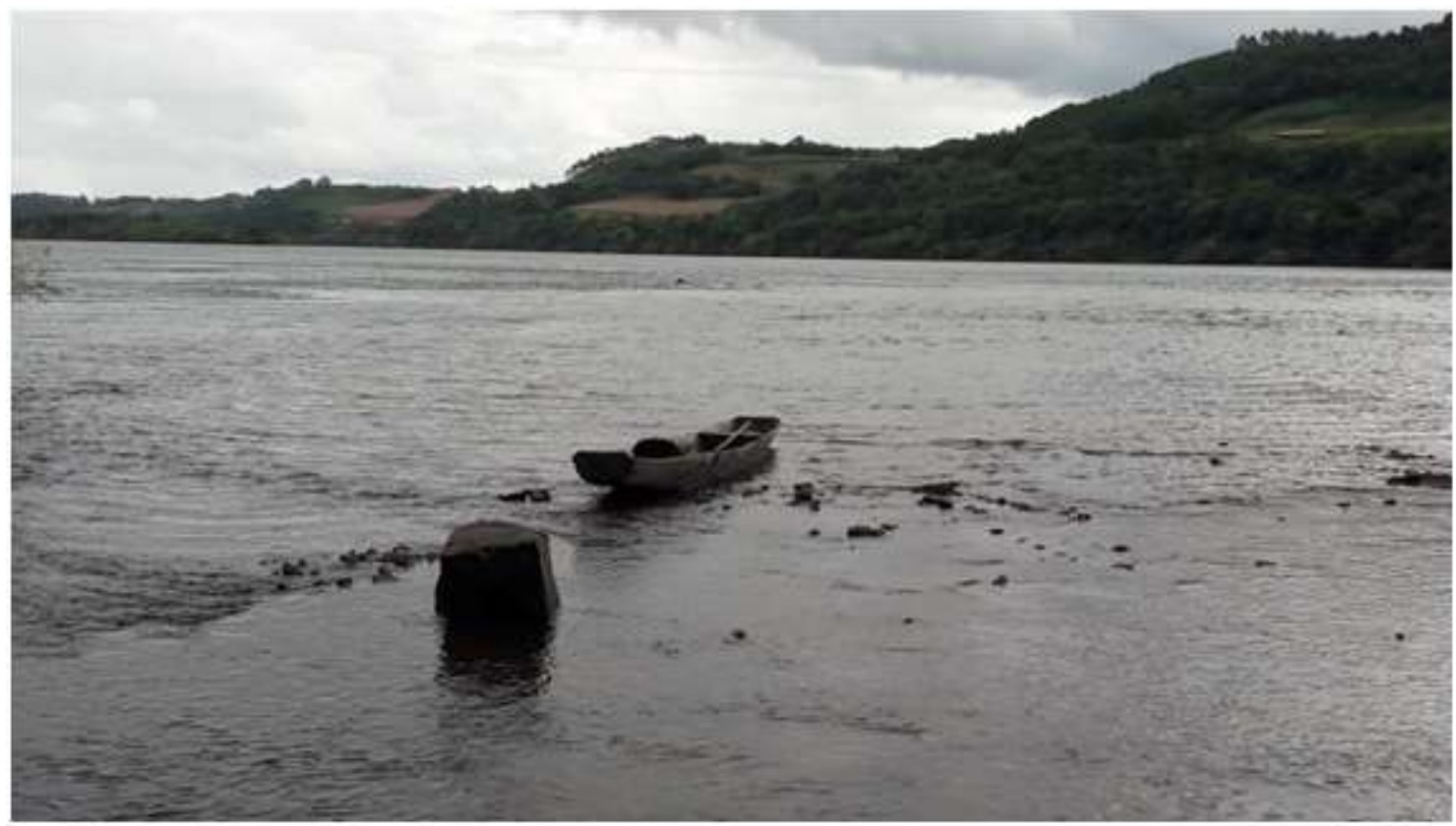

Fonte: Foto de Jaisson Teixeira Lino 


\section{A paisagem como objeto de estudo da história ambiental}

Dentro do campo historiográfico que se convencionou chamar de história ambiental ${ }^{3}$ vem-se produzindo uma gama de trabalhos que dialogam com os mais diferentes aspectos do que conhecemos como meio ambiente. Assim, diferentes compartimentações ambientais, como rios, matas, solos, climas, dentre outros, estão sendo analisadas em separado ou relacionadas sob a lente da história. A paisagem pode ser considerada como um objeto de estudo da história ambiental, embora o termo careça de uma definição mais rígida.

Trabalhar a conceituação dos termos empregados na pavimentação de um estudo impõe, naturalmente, dificuldades relativas às peculiaridades de cada termo. Entretanto, essa é uma lida indispensável, sobretudo quando o conceito em tela foi - e é - objeto de diferentes olhares que oscilam entre os campos da ciência e das manifestações artísticas. Assim, a paisagem - conceito abordado neste artigo - implica determinados riscos para o seu manuseio e requer atencioso cuidado para a sua mais apropriada utilização.

Intuitivamente, parece certo imediatismo a associação ao terreno científico da Geografia ${ }^{4}$ assim que o termo "paisagem" mostra-se ao leitor. Contudo, como alertam Alves e Souza de Deus, deter-nos tão somente sobre a noção geográfica de paisagem "é um risco, uma vez que a pluralidade de abordagens a respeito é imensa" (2014, p.71). Assim, os referidos autores justificam as observações sobre a paisagem oriundas da história da arte, da literatura, da pintura e do turismo.

Estudiosos de variados campos do saber lançaram diferentes olhares sobre o conceito de paisagem e, obviamente, obtiveram distintas conclusões, como veremos a seguir. Todavia, ao tentar-se estabelecer um denominador comum entre as plurais conclusões dos autores, pode-se admitir - sem relevante receio - que a compreensão do conceito de paisagem não se reduz apenas às emanações materiais que escapam do objeto, mas implica também aspectos intangíveis atribuídos ao próprio objeto, fazendo da paisagem um organismo vivo, produto e produtor de conteúdo num dado cenário histórico, num período de tempo específico.

Contudo, e por razões óbvias, nos aproximamos mais daqueles conceitos de paisagem que levam em conta sua historicidade, isto é, de como a história de um determinado espaço geográfico ocupa lugar privilegiado em uma dada abordagem. Longe de influenciar lateralmente, a história ocupa lugar central na análise, mostrando que as paisagens são o que são no presente em decorrência das transformações pretéritas. Nesse sentido, destaca-se a abordagem do geógrafo humanista sinoamericano Yi-Fun Tuan, cujos trabalhos podem ser inseridos sob a expressão "geografia histórica". Portanto, o tempo ocupa lugar privilegiado em suas análises sobre a paisagem e suas duas grandes

\footnotetext{
${ }^{3}$ Não é o foco deste trabalho tratar da história da história ambiental. Existem alguns trabalhos que exploram o tema, dentre os quais sugerimos Worster (1991), Drummond (1991) e Duarte (2005).

${ }^{4}$ As noções de paisagem na Geografia estão subordinadas às diferentes escolas teóricas, a grosso modo divididas entre as geografias saueriana, humanista e cultural. Para uma síntese sobre paisagem e ramos teóricos do campo geográfico, ver Corrêa (1995) e Caetano e Bezzi (2011).
} 
compartimentações - espaço e lugar. Um dos conceitos centrais e que nos interessa neste momento é o de "experiência", que pode ser definido como as pessoas constroem seu mundo na paisagem a partir de sentidos, ações e pensamentos, espalhando pela paisagem suas histórias por meio de transformações mentais e materiais (TUAN, 2012; 2015).

Os historiadores têm desenvolvido estudos sobre a paisagem em perspectiva diacrônica desde muito antes do advento da história ambiental, em meados da década de 1970 (WORSTER, 1991), contribuindo sobretudo para a análise das transformações do território e os diferentes processos de apropriação da natureza pela cultura. Contudo, com o estabelecimento da história ambiental como um campo de saber acadêmico consolidado, os estudos da história da paisagem tiveram um grande crescimento, conforme observa Regina Horta Duarte: "se a indagação das paisagens não é uma prática nova entre historiadores, estudos recentes de história ambiental a elevaram à dupla condição de objeto histórico e documento histórico" (DUARTE, 2005, p. 60).

Por isso, identificar possíveis leituras históricas através da paisagem e como se deu o seu uso no município de Iraí-RS, num cenário de conflito entre os não indígenas e os Kaingang, entre os anos de 1920 e 1980 - período que compreende o início da colonização e a criação da reserva florestal daquele município - é a intenção primeira deste estudo. Convém salientar que à paisagem analisada sobrepuseram-se diferentes concepções: a projeção não indígena da paisagem associando-a a um painel de natureza estática e intocada, por isso passiva de preservação através - inclusive - de distanciamento, e a visão Kaingang, que estabelece um relacionamento estreito entre o indígena e o ambiente e, portanto, pressupõe aproximação entre o homem e a natureza.

Para tanto, utilizam-se como fontes primárias documentos escritos, dentre os quais se destacam duas leis municipais da década de 1970 - a Lei 798 A/73 e a Lei n $921 / 79$, uma das quais trata da criação da Reserva Florestal de Iraí - e depoimentos colhidos no Livro de Registro do Balneário Osvaldo Cruz, que contém impressões de turistas sobre a paisagem da cidade publicadas no livro de 1954, de autoria de Martin Fischer.

Ao discorrer sobre "paisagem", Schama (1996), em sua obra Paisagem e Memória, assinala esse elemento enquanto uma fonte histórica que, como tal, pode ser lida e, consequentemente, interpretada. Mas não só. O autor avança na sua análise e demonstra como a paisagem foi usada como ingrediente para a construção, por exemplo, de identidades nacionais/culturais, especialmente a germânica.

Nesse sentido, Hirsh (apud Symanski,2007, p. 12) ajuda a compreender a paisagem como produto e produtor de um tecido histórico capaz de oferecer indícios sobre uma determinada sociedade, situada num período temporal definido, ao afirmá-la como um "processo que relaciona a experiência da vida social cotidiana (foreground) a uma idealizada existência potencial (background)". Segundo o mesmo autor, "foreground" envolve os aspectos concretos do cotidiano, como imagem, interior e lugar, enquanto o "background" relaciona-se ao plano imaterial, metafísico, e engloba os conceitos de espaço e representação. Assim, esses dois conceitos alimentam-se mutuamente numa relação de 
explicação e dependência, isto é, projetam-se e são projetados, pela e sobre a paisagem analisada. Os dois conceitos precedentes são basilares, neste estudo, para a análise da paisagem iraiense.

\section{A paisagem de Iraí e a presença Kaingang}

"Conheci as Águas do Mel em 1919, quando tudo isto era 'sertão cerrado e umbroso' (...) Hoje, Iraí, a cidade - jardim, é uma joia urbanística de fino lavor, lindamente engastada no seio da floresta". ${ }^{5}$ Essas são as palavras de Darcy Pinto, escritas no livro de registro de visitantes do Balneário Osvaldo Cruz, chamado "Livro de Ouro da Estância Hidromineral de Iraí", na data de 7 de março de 1953. O trecho foi transcrito da imagem a seguir:

Figura 3: Relato registrado por Darcy Pinto em 7 de março de 1953.

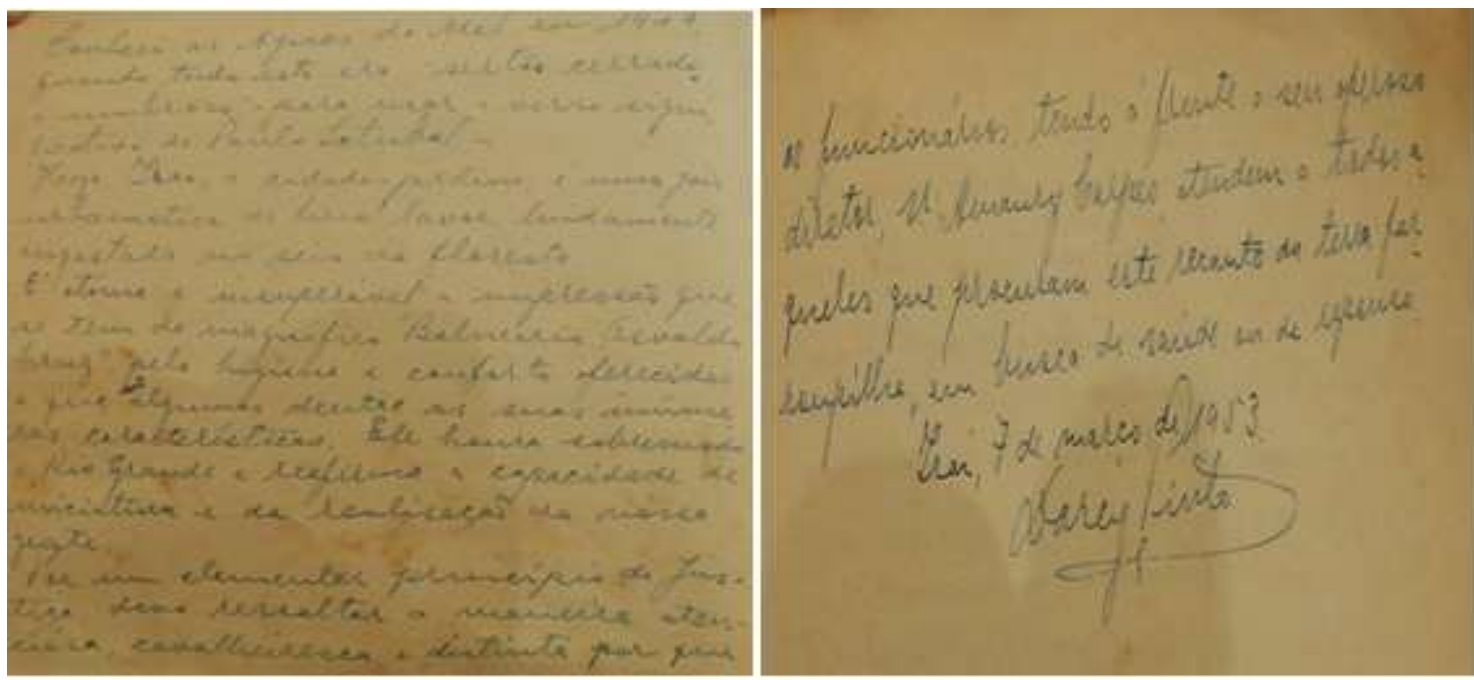

Fonte: Livro de Registro do Balneário Osvaldo Cruz. Fotos de Fábio Araújo.

A fonte acima contribui para o estudo na medida em que o autor das palavras transcritas, embora as tenha registrado apenas em março de 1953, menciona sua passagem anterior no ano de 1919 e, num esforço de memória, descreve a impressão marcada pela paisagem daquele ano, uma paisagem "umbrosa". A escolha desse adjetivo, inspirado num poema, favorece o entendimento de que a paisagem de 1919 ofereceu naturais obstáculos à empreitada urbanizadora. Não obstante, no tempo "hoje" - 1953 -, percebe-se a manutenção e manipulação da paisagem que cede ao avanço urbanístico sem, no entanto, renunciar por completo ao seu espaço, pois, como descreve o visitante, Iraí era uma cidade situada "no seio da floresta".

Na sua obra de 1954, intitulada Iraí - Cidade Saúde, Martin Fischer inicia a sua descrição da paisagem iraiense da metade do século $X X$, afirmando que Iraí se situa e se "descortina num magnífico panorama, e

\footnotetext{
${ }^{5}$ O poema em referência é de autoria do poeta Paulo Setubal (1893-1937), chamado "Vida Campônia", publicado em 1920, na obra Alma Cabocla.
} 
se nos apresenta como encerrada numa paisagem fantasticamente linda e pitoresca, que até hoje (...) muito conserva da sua encantadora originalidade" (FISCHER, 1954, p.9).

O uso dos adjetivos "linda" e "pitoresca" indica um efeito de contemplativa admiração gerado no observador, num primeiro momento pelo aspecto imediatamente estético - "linda". Num segundo instante, que pode ser entendido como um momento transitório, o termo "pitoresco", isto é, algo digno de ser pintado, revela não apenas uma apreciação pelo belo, mas, também, uma projeção particular sobre a paisagem na necessidade de registrá-la em tela. Ao avançar nas suas impressões, o autor anteriormente referenciado justifica essa preocupação ao afirmar que a paisagem iraiense conservara sua "originalidade".

Outro relato constante no livro do Balneário Osvaldo Cruz e citado por Martin Fischer, registrado em 30 de novembro de 1948, é o do então cônsul-geral do Uruguai, Miguel Vieyte, quando assim afirma sobre a paisagem iraiense:

Sus bellezas naturalles; su mato agreste; la magestuosidad de las "Sierra Del Uruguay" constituyen motivos de sugestiva atracción y profundos êxtases, de infinito soláz para las mentes e los físicos abrumados por el contínuo esfuerzo. Tanta riqueza panorâmica y tanta lujuria selvativa, mecida por el concierto sublimemente arrulador del Sairá, Sabiá, van alcançando el refinamiento de sus artistas por labor fecunda, inteligente y tenaz de sus autoridades. [...] Que pronto veamos la merecida evolucion de "La Ciudad de los Jazmines", como poderiamos llamar a Iraí, hacia el gran centro turístico anhelado, com los motivos de esparcimiento que la mano del hombre puede crear com facilidad entre tante belleza natural (FISCHER, 1954, p. 72).

O que, de imediato, se depreende do relato acima é a impressão causada pela paisagem iraiense ao turista uruguaio. Uma impressão notadamente orientada pela leitura estética do objeto. A maneira como a paisagem afeta o veranista, como ele a percebe, pode ser observada nas escolhas dos adjetivos e expressões usadas para descrever a paisagem, tais como "belezas naturais", "mata selvagem", "riqueza panorâmica" e "luxúria selvagem". Num segundo momento, o turista revela a sua particular projeção sobre a paisagem, sobretudo no que concerne ao modo como ela deveria ser, ao seu juízo, aproveitada e manipulada para permitir a construção do "grande centro turístico almejado" com a oferta de "meios de entretenimento". Tarefa criativa que, de acordo com o mesmo, seria facilitada pelo potencial estético natural da paisagem.

Do ano de 1952, destacam-se três relatos registrados no livro do Balneário Osvaldo Cruz e publicados na obra de Fischer (1954, p.73). O primeiro, de Raul Pilla, professor catedrático que, em 27 de janeiro daquele ano, descreveu Iraí como uma cidade "naturalmente dotada de uma água virtuosa, possuidora de um balneário original e moderno, 
cercada de uma paisagem encantadora". Em 31 de janeiro, o desembargador Augusto Loureiro Lima relatou que "a Natureza dadivosa soube premir Iraí com suas magníficas termas, requintou, ainda, recamando-a de verdes e luxuriantes selvas que nos extasiam e encantam". Outro desembargador, Moreno Loureiro Lima, em 2 de fevereiro escreveu que o município de Iraí era "emoldurado em verdura perenemente luxúria, cujo frescor e cheiro característico de selva tropical temperam o halitejar morno das fontes termais...". Sublinham-se desses três relatos elementos como "água", "natureza", "termas", "selvas" e termos que ajudam a compreender as características da paisagem como "virtuosa", "encantadora", "dadivosa", "magnífica".

Percebe-se, desse modo, a paisagem iraiense não como um objeto estático, tão somente um receptáculo de reflexões de paradigmas conceituais contemporâneos, mas, antes disso, como um organismo vivo capaz de influenciar seus observadores e neles despertar inquietações, compreensões que permeiam as manifestações que, por algum motivo ou de alguma forma, lograram o fato de serem registradas para a posteridade.

A seguir, Fischer (1954), ao caminhar nas suas descrições sobre a cidade de Iraí, oferece algumas palavras que permitem conclusões sobre a presença indígena no território compreendido na observância da paisagem e, também, inferências sobre o caráter dicotômico da descrição desses indígenas, opondo, de um lado, a sua indumentária, considerada desconectada do estereótipo projetado sobre o indígena, e os seus instrumentos de caça tradicionais, qualificados como "primitivos":

Pois, neste recanto às margens do majestoso Rio Uruguai, é um dos poucos lugares do Rio Grande do Sul, onde ainda se pode achar a natureza em virginidade incólume, e onde ainda há o porco do mato e bugio, e onde também podemos encontrar-nos, em desertos atalhos, com índios caçadores, usando suas armas primitivas. Não são mais aqueles rapazes cor de bronze que, antes, percorreram as vastas matas antiquíssimas, os verdadeiros senhores do sertão: os de hoje já são, por assim dizer, 'lambidos' pela civilização; vestem camisas, calça e até usam chapéu, da maneira de homens civilizados. Mas, nos dias que correm, ainda preferem a caça de arco e flecha, como fizeram seus ancestrais há centenas ou milhares de anos (FISCHER, 1954, p. 9).

Para além da presença indígena, claramente manifesta nas palavras de Martin Fischer, o autor indicou a imponência da natureza na paisagem e fez apontamentos sobre a fauna denunciando a presença do porco-domato e do bugio. Essa descrição permite inferências sobre o portfólio de caça dos indígenas, hábitos alimentares e a criação de animais dos habitantes do território correspondente à paisagem relatada.

Contudo, não só a presença indígena é objeto de registro escrito por parte de Martin Fischer, mas também a relação dos Kaingang com os 
não indígenas, especialmente os turistas ${ }^{6}$. Do encontro entre dois diferentes atores no cenário paisagístico, o indígena enquanto ator local e o turista enquanto ator visitante, resulta um composto estimulado pela paisagem e que, ao mesmo tempo, atua sobre a própria paisagem, pois, dos traços da paisagem descrita pelo autor, muitos são justificados pela origem indígena, como é possível ler nas palavras seguintes, em que os indígenas vendiam:

aos banhistas toda espécie de animais amansados, tais como filhotes de mico ou de coati; tucanos, papagaios e caburés 'portadores de boa sorte'. Oferecem à venda arcos e flechas, bem como chapéus, leques, cestinhos e esteiras, trançados de palha, etc. Deixam-se fotografar já sem a menor estranheza. Há muito tempo que compreenderam ser uma 'curiosidade' para os banhistas que, em parte, vêm de muito longe, dos grandes centros civilizados, e, em sua esperteza primitiva, aproveitamse bem da situação (FISCHER, 1954, p. 13).

A partir da cena descrita nas linhas acima, pode-se inferir que a implicação da paisagem sobre os turistas repousa, por contato primeiro, numa tez de exotismo; afinal, os indígenas já haviam entendido a "curiosidade" despertada por eles. Essa impressão derivava do contato visual imediato e, assim, Tuan ajuda a pensar essa reação ao afirmar que a "avaliação do meio ambiente pelo visitante é essencialmente estética. É a visão de um estranho. O estranho julga pela aparência" (2012, p.97).

Dessa forma, da leitura da paisagem iraiense da primeira metade do século XX, salientam-se como principais características a natureza, referenciada como "virgem", ou em estado "original", e o indígena mencionado no contato com os turistas, justificado também pelo comércio do seu artesanato, mas, principalmente pela presença indígena nos caminhos da mata.

O próprio título do livro de Martin Fischer, Iraí - Cidade Saúde, já indicava a percepção que pairava sobre a paisagem da cidade na primeira metade do século XX. Pois bem, nos parágrafos precedentes, verifica-se uma embrionária preocupação com a preservação da natureza iraiense, motivo de tão elogiosos comentários inscritos por Fischer e por turistas que visitaram Iraí.

Essa inicial preocupação com a preservação da natureza indicara não somente um sentimento de zelo e conservação pela paisagem, mas uma ideia de que o processo de urbanização e o consequente contato do homem com a natureza acarretaria, inevitavelmente, a degradação do ambiente natural. Dessa concepção, derivam duas prospecções, sendo, a primeira, uma relação dicotômica entre homem e natureza, e a segunda, uma condenação da natureza à pena da inércia, à imutabilidade.

A reflexão anterior encontra refúgio nas proposições de Arruda,

\footnotetext{
${ }^{6}$ Como anteriormente relatado, Iraí possui uma importante estância hidromineral e, por decorrência, atrai anualmente turistas, sobretudo oriundos do sul do Brasil, que utilizam as águas principalmente para fins terapêuticos e medicinais.
} 
quando este autor disserta sobre a criação de unidades de conservação no Brasil e observa que o modelo adotado para tal instituição guarda influências estadunidenses e deriva, basicamente, da ideia de que a "domesticação de toda a biosfera pelo ser humano é inevitável, sendo necessário e possível conservar pedaços do mundo natural em seu estado originário, antes da intervenção humana" (1999, p.83). Dessa forma, farse-ia imperativa a necessidade de preservar espaços em que o homem pudesse contatar a natureza no seu estágio original - premissa básica dessa concepção, para fins religiosos ou científicos.

O cenário que se consolidou em Iraí entre as décadas de 1920 e 1960 conduziu o Poder Público municipal à criação da Lei n. 798 A/73, que dispunha sobre as reservas florestais iraienses, e tamanha era a preocupação com a agressão à natureza que o artigo $4^{\circ}$ dessa lei previa a proibição da "derrubada e a extração de árvores, ainda que mortas, bem como a extração de mudas de árvores, de flores ou de qualquer forma de vegetação, de minérios, areias, cascalhos, saibros" dos perímetros que compreendessem as áreas de reservas florestais da cidade.

A lei não se deteve apenas à proibição do desmatamento, como exposto no parágrafo acima, mas incutiu a necessidade de uma ação preventiva através da educação municipal, que seria o terreno propício para a conscientização da população local. Assim sendo, o artigo $8^{\circ}$ da Lei 798 A/73 obrigava as escolas municipais a ministrarem "aulas sobre conservação da natureza em geral, e especialmente sobre a necessidade da conservação da flora e da fauna como fatores de equilíbrio ecológico".

Evidentemente, as áreas definidas como reservas florestais não correspondiam às áreas situadas no perímetro urbano e, como já era sabido, a paisagem humana iraiense era composta por elementos indígenas. Dessa condição resulta o entendimento de que o indígena oferecia perigo à preservação da natureza, sendo necessário o seu afastamento da área delimitada como reserva.

Não obstante, os Kaingang observam o "mato" com um valor simbólico que se associa ao sagrado; afinal, algumas tintas utilizadas para a pintura corporal são extraídas do carvão de determinadas plantas e representam, inclusive, uma ideia de proteção para os indígenas. No entanto, os Kaingang mantêm uma relação paradoxal com o "matão", pois do mato não apenas provêm elementos evocados para a sua proteção, mas também um grande temor para os Kaingang, conforme indica Silva (2002. p.195-196).

Contudo, Regina Duarte (2005) contrapõe essa premissa ao enfatizar que não somente é possível a permanência de populações que estão bem estabelecidas e adaptadas dentro de reservas ambientais, como também destaca que elas podem contribuir para a manutenção e o equilíbrio biológicos. Outro ponto crítico destacado é o modo como os habitantes de reservas recém-criadas são tratados:

Uma das questões mais discutidas atualmente é o autoritarismo presente na criação dessas áreas. Definida por cientistas e técnicos, acarreta a retirada de inúmeras pessoas que viviam ali por inúmeras gerações, com 
práticas consideradas de baixo impacto na natureza (DUARTE, 2005, p.25).

Conforme Grassi, os Kaingang se estabeleceram, a partir de 1949, "à margem direita do Rio do Mel (...). Aí os índios ergueram uma ou duas palhoças improvisadas, cobertas de folhas de taquara" (2012, p.97). À mesma margem direita do Rio do Mel estava situado o chamado "Bosque Sagrado", do qual tratava a Lei n. ${ }^{0}$ 921/79 que dispunha sobre a criação das Reservas Florestais de Iraí, no artigo $2^{\circ}$ da referida lei, mais especificamente. Logo, sobrepuseram-se comunidade indígena e reserva florestal numa única paisagem.

Figura 4: Aldeia-sede da Terra Indígena Iraí, de Iraí-RS.

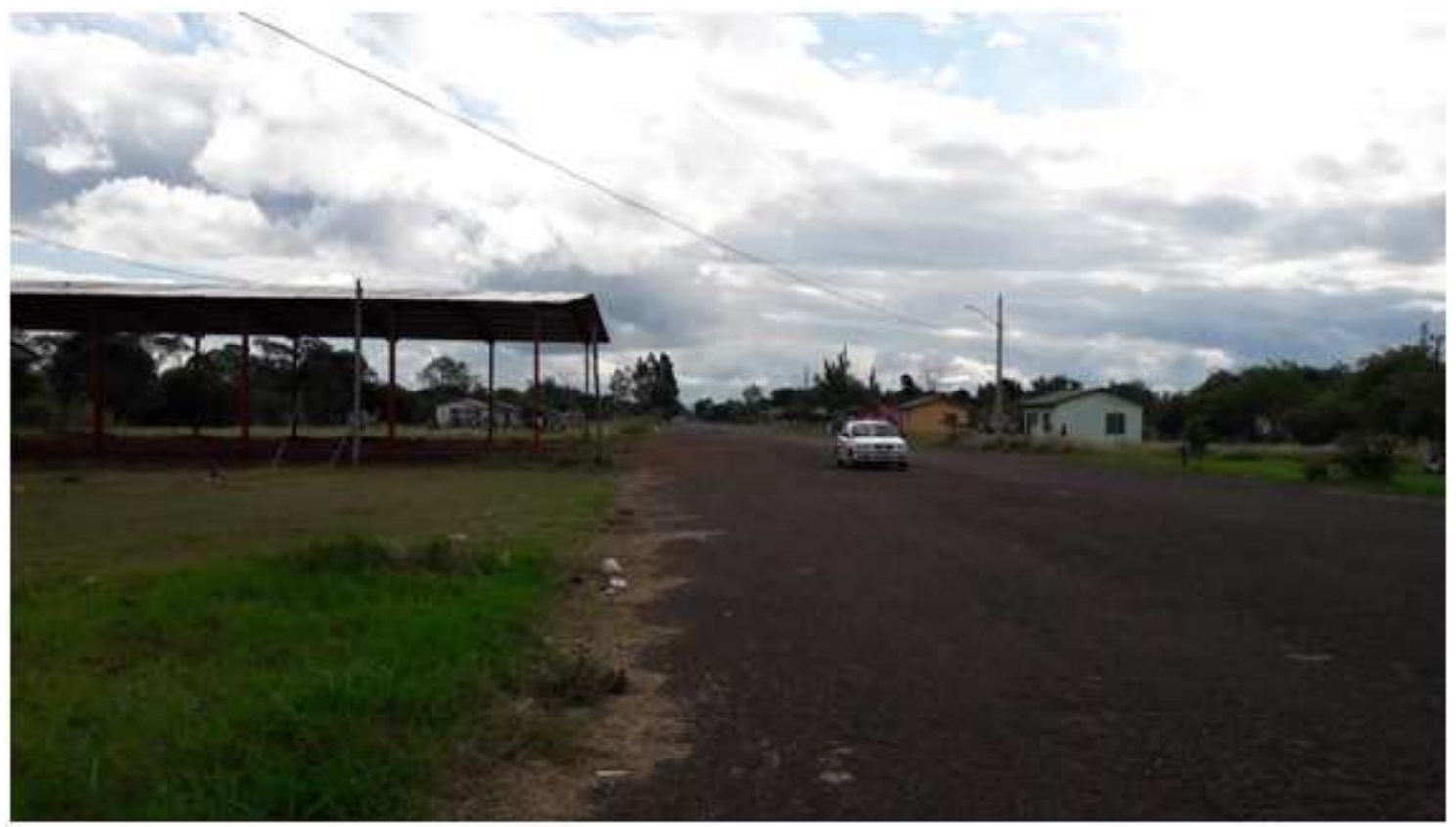

Fonte: Foto de Jaisson Teixeira Lino

A ocorrência concomitante da presença indígena e da reserva florestal sobre a paisagem do Bosque Sagrado não seria, porém, tolerada conforme a mesma Lei n. $^{\circ} 921 / 79$, pois, no seu $4 .^{\circ}$ artigo, que discriminava as finalidades do parque florestal, o dispositivo legal determinava o "desassentamento de intrusos existentes na área do Parque". Ora, embora não tenha especificado quem eram os "intrusos", restou claro que se tratavam dos Kaingang.

Com a promulgação da Lei n. ${ }^{\circ} 921 / 79$, a presença indígena - no seu próprio território, diga-se - passou a ser criminalizada. E, a partir da criação dessa Reserva Florestal, a tensão entre os Kaingang e a sociedade não indígena aumentou e evoluiu para um processo de articulação dos indígenas para demarcação do seu território tradicional, que, evidentemente, encontrou a resistência da comunidade não indígena, conforme ilustram as palavras de Grassi: 
Ensejar que a Reserva Florestal de Iraí seja, pura e simplesmente, demarcada como terra de ocupação 'tradicional' dos índios se constitui num verdadeiro ataque ao bom senso e na negação de todo o conteúdo histórico que o passado, com sacrifícios, estudos científicos e muito carinho nos legou, elevando a Estância Hidromineral de Iraí à condição de mais importante do Sul do País e de fama internacional (GRASSI, 1992, p. 25).

Com o advento do instrumento legal que criou a Reserva Florestal de Iraí, estabeleceu-se também o conflito entre dois paradigmas conceituais que se debruçaram sobre a mesma paisagem, isto é, de um lado a visão não indígena da necessidade de preservar a natureza pretensamente intocada e, de outro, a lógica Kaingang que reconhecia como seu o território objeto da lei de criação da reserva florestal. Essa mesma paisagem foi cenário de um conflito que opôs Kaingang e não indígenas num pleito por demarcação territorial.

\section{Questões para reflexão}

A paisagem iraiense para o período proposto neste estudo não satisfaz as características que se espera apenas da descrição minuciosa de um viajante ou visitante atento e sensível aos seus traços. Antes disso, a paisagem presente neste texto revelou-se um painel vivo, passivo de leitura e compreensão, um terreno fértil de onde brotaram não só descrições, mas conflitos, projeções e interpretações.

Assim, a paisagem iraiense serviu de alicerce para a constituição da imagem de Iraí como "Cidade Saúde", como o título da obra de Martin Fischer sugere. Essa é apenas uma entre as possíveis interpretações que a paisagem iraiense instiga, mas pode-se admitir que a paisagem iraiense consolidou-se entre os turistas e a comunidade não indígena, mitologicamente, como um extrato de natureza em estado "original". Segundo Tuan como um estrato de natureza, via de regra existem dois tipos de espaços míticos:

Podem-se distinguir dois tipos principais de espaço mítico. Em um deles, o espaço mítico, é uma área imprecisa de conhecimento envolvendo o empiricamente conhecido; emoldura o espaço pragmático. No outro, é o componente espacial de uma visão de mundo, a conceituação de valores locais por meio da qual as pessoas realizam suas atividades práticas (TUAN, 2015, p. 95).

Por essa razão, emergiu, entre os adeptos dessa ideia, a necessidade de preservar a paisagem, nos moldes apontados por Arruda (1999), isto é, numa preservação mediante o afastamento entre a paisagem e o homem. Nesse movimento, foi considerada a presença 
indígena na paisagem e a necessidade de afastá-los de seu próprio território, fato que alimentou a eclosão de um litígio para a demarcação da terra indígena sobreposta à Reserva Florestal de Iraí.

Um outro ponto crítico e que necessita ser mencionado é que, via de regra, sociedades ditas industrializadas - ou capitalistas, ou complexas, ou modernas, etc. - possuem visões e atitudes diametralmente opostas sobre a natureza. Não se trata de afirmar que os povos indígenas mantiveram um sentido de extrema conservação da natureza, pois, como portadores de cultura, modificaram o ambiente de maneira a marcar a paisagem com sua história cotidiana plantando, habitando, caçando, ritualizando. Por outro lado, não é o caso de concordar com Dean (1996), que advoga uma maciça destruição da Mata Atlântica brasileira por parte dos povos Tupi da costa. O que aconteceu, e vem acontecendo, é uma exploração da paisagem natural por parte dos povos tradicionais de maneira muito mais equilibrada e, portanto, menos destruidora da natureza.

É possível fazer uma leitura histórica de Iraí-RS, entre os anos de 1920-1980, orientada a partir da análise da paisagem. Nesse sentido, tem-se a paisagem como fonte histórica e fértil objeto de análise historiográfica. Porém, para a leitura da paisagem nos termos propostos é necessária a devida prudência metodológica e a pavimentação de um referencial que permita essa investigação analítica. Longe de considerar - ambiente como determinante em acontecimentos passados, advogamos aqui que a natureza é agente influenciadora e, muitas vezes, transformadora da cultura. Assim, inserimos a história natural no tempo social e cultural de Iraí, mostrando que ocorre uma constante troca dialética entre cultura e natureza na história da humanidade, seguindo o que José Augusto Drummond considera uma mudança de paradigma na história, em particular, e nas ciências sociais, em geral: "significa que o cientista social dá às 'forças da natureza' um estatuto de agente condicionador ou modificador da cultura" (DRUMMOND, 1991, p.181).

Realizamos aqui a análise de alguns documentos referentes ao objeto de estudo. Contudo, existem inúmeras fontes documentais escritas, pictóricas, orais - que fornecem elementos para o debate sobre os discursos da paisagem de Iraí, tendo como pano de fundo os conflitos sociais e étnicos na região. Esperamos ter contribuído aqui para a questão a partir da análise de algumas fontes sobre o assunto, cabendo a trabalhos futuros ampliar a questão, sobretudo no que tange à memória oral da comunidade indígena Kaingang residente da Terra Indígena de Iraí. 


\section{Referências Bibliográficas}

ALVES, R. C; SOUZA de DEUS, J. A. O Não-Lugar e as Paisagens Do Medo: Nuances Topofóbicas. Revista Eletrônica Geoaraguaia. Barra do Garças-MT. Vol. 4, n.1, p. 7082. Jan./Jun.. 2014.

ARAÚJO, F. Entre figurantes e antagonistas: os Kaingang no enredo da demarcação da Terra Indígena Iraí - RS. 2018. 118 fl. Dissertação (Mestrado em História) - Programa de Pós-Graduação em História, Universidade Federal da Fronteira Sul - UFFS, Chapecó, 2018 .

ARRUDA, R. "Populações Tradicionais" e a proteção dos recursos naturais em unidades de conservação. Revista Ambiente \& Sociedade, Ano II, n. 5 - 2º semestre de 1999.

CAETANO, J. N.; BEZZI, M. L. Reflexões na geografia cultural: a materialidade e a imaterialidade da cultura. Sociedade e Natureza, vol. 23, n. 3, 2011, p. 453-466.

CORRÊA, R. L. A Dimensão Cultural do Espaço: Alguns Temas. Espaço e Cultura, Ano I, 1995, p. 1-22.

DEAN, W. A Ferro e Fogo - a história da devastação da Mata Atlântica brasileira. São Paulo: Companhia das Letras, 1996.

DRUMMOND, J. A. A história ambiental: temas, fontes e linhas de pesquisa. Estudos Históricos, vol. 4, n. 8, 1991, p. 177-197.

DUARTE, Regina Horta. História \& Natureza. Belo Horizonte: Autêntica, 2005.

FISCHER, M. Iraí Cidade Saúde - Trechos Característicos de Sua História. Ijuí, 1954.

GRASSI, F. D. Iraí, ecologia e índios. Frederico Westphalen-RS: Gráfica Barril, 1992.

IBGE. Geografia do Brasil. Vol. 5: A Região Sul. Rio de Janeiro: IBGE, 1977.

IRAÍ. Lei 798 A, de 28 de dezembro de 1973.

IRAÍ. Lei no 921, de 20 de junho de 1979.

LAC, F. O Turismo e os Kaingang na Terra Indígena de Iraí/RS. 2005. Dissertação (Mestrado) -- Universidade Federal do Paraná.

LINO, J. T. O povoamento indígena no Sul do Brasil: as contribuições da arqueologia e da história. In: RADIN, J.C; VALENTINI, D.J; ZARTH, P.A. (Orgs). História da Fronteira Sul. Porto Alegre: Letra\&Vida; Chapecó-SC, UFFS, 2015.

RADIN, J. C. Um olhar sobre a colonização da Fronteira Sul. In: RADIN, J.C; VALENTINI, D.J; ZARTH, P.A. (Orgs). História da Fronteira Sul. Porto Alegre: Letra\&Vida; Chapecó-SC, UFFS, 2015.

RIO GRANDE DO SUL. Secretaria do Planejamento, Mobilidade e Desenvolvimento 
Regional Perfil Socioeconômico Corede Médio Alto Uruguai. Porto Alegre, 2015.

SCHAMA, S. Paisagem e Memória. Tradução: Hildegard Feist. São Paulo/SP: Companhia das Letras, 1996.

SILVA, S. B. Dualismo e cosmologia Kaingang: o Xamã e o domínio da floresta. Horizontes Antropológicos, Porto Alegre, ano 8, n. 18, p. 189-209, dezembro de 2002.

SYMANSKI, L. C. P. O Domínio da Tática. Práticas religiosas de origem africana nos engenhos de Chapada dos Guimarães (MT). Revista Latino-Americana de Arqueologia Histórica. Vol. 1, n. 2. Jul. - Dez./2007.

TUAN, Yi-Fu. Espaço e Lugar - A perspectiva da experiência. Londrina: EdUEL, 2015.

TUAN, Yi-Fu. Topofilia: um estudo da percepção, atitudes e valores do meio ambiente. Londrina: Eduel, 2012.

WORSTER, D. Para fazer história ambiental. Estudos Históricos, vol. 4, n. 8, 1991, p. 198-215. 